\title{
Application of Ecological Architecture Principles in Eco Resort Design at Pemenang, Lombok
}

\author{
Surya Subagya ${ }^{1}$, Ciptadi Trimarianto ${ }^{2}$ \\ Bachelor Degree of Architecture Study Program \\ Faculty of Engineering-Udayana University \\ Jimbaran \\ surya.subagya@yahoo.co.id \\ Architecture Study Program \\ Faculty of Engineering-Udayana University \\ Jimbaran
}

\begin{abstract}
Lombok Island seems to be a favorite holiday destination for international and domestic tourists, because it has many tourists destinations, one of which is North Lombok Regency. This condition greatly impact on increasing regional income, individual of communities from service accommodation to tourist. However, judging from the interest of tourist visits which increase every year, the avaibility of facilites in terms of quantity and quality has not been balanced. For example, resort as a form of tourism accommodation are the most sought after by tourist, because the have the most complete facilities to pamper tourist while enjoying the beauty of the sorrounding environment. In fact, the condition of tourism accommodation especially in the subdistrict of Pemenang can be said to have not developed according to the demand and needs of tourist. The existence of resorts as a place to serve tourists in the sub-district of Pemenang is very minimal, this can be said because the number of accommodation is dominated by homestay class which in general has incomplete facilities. Beside that, it needs to be supported by special treatment in planning a resort with an eco-architecture approach to reduce the enviromental impact of planning this resort. This approach in planning eco-resort is combined with combining the local architecture to be in harmony with the conditions and atmosphere of the sorrounding environment. So, tourists can be take a vacation and relax while feeling the atmosphere of the sorrounding environment that is presented in this tourist accommodation
\end{abstract}

Index Terms - resort, eco architecture, reduce, local of architecture, environment.

\section{INTRODUCTION}

Resort is a temporary place to stay that has a variety of special facilities used by tourists for activities to stay, eat and drink, vacation, relax, exercise, and travel around sambal to enjoy the natural beauty that is around the resort [1]. Eco Architechure or ecological architecture is basically designing, building up to the operational stage of a building in ways that are able to minimize negative impacts on the surrounding environment [2], ecological architecture can also be interpreted as a concept in designing a building which has a minimal negative impact on the environment compared to conventional design methods in general [3]. So that the eco resort is one of the tourism accommodation containers in the form of resorts that serve services to guests including, lodging, eating and drinking, entertainment, recreation and sports while enjoying the beauty of the surrounding nature but with operational service systems that are environmentally 
friendly so as to reduce the impact on the environment. Pemenang Subdistrict has many destinations so it makes a favorite tourist destination for foreign and domestic tourists who are on vacation to the island of Lombok, but this condition has not been matched by the quantity and quality of good tourism accommodation. Therefore, the eco resort plan in Pemenang Subdistrict is quite appropriate considering the Winner Subdistrict is the connecting route of the northern Lombok tourist destination (Gili Trawangan as the belle of the resort) with the tourist destination on the western part of Lombok Island and is expected to be able to improve the surrounding economy.

In supporting the success of an eco-friendly resort plan, several approaches are needed, both from knowing the theories, principles, and design strategies in realizing environmentally friendly resorts. Efforts that can be done both from the design of buildings that are able to be sensitive to climate regarding the location and natural resources available in the vicinity, saving energy consumption, applying environmentally friendly materials and easily obtained in the surrounding environment, harmony with the environment both from design, selection material to the utilization of natural resources. The implementation of this approach can be implemented in presenting a green roof, optimizing natural lighting and ventilation, applying renewable energy sources, and proper wastewater treatment. On the other hand, the emphasis on the local atmosphere of the local architecture needs to be emphasized and integrated with an environmentally friendly building approach so that later the resort is expected to be able to strengthen the local local identity while having its own selling points at the resort and be able to become a reference in the planning of environmentally friendly resorts.

\section{RESULT AND ANALISYS}

\section{A. Implementasi Langgam Arsitektur Sasak}

Environmentally friendly architecture talks about the harmony of the environment both from the appearance of buildings, the application of materials to the applied architectural styles, one of which is the style of Sasak granary architecture, as in some buildings with supporting facilities, such as lob-by and main facilities such as room units in eco resort.

The lobby is a supporting facility at the eco resort that serves as a place to receive the first time in a resort which at the same time as a facility that gives a first impression or first impression to visitors, so the lobby must be able to lift and strengthen the local local atmosphere both architectural and environmental values around with the appearance of Sasak barns which are developed both from the dimensions, structure and use of materials. (see figure $1)$.

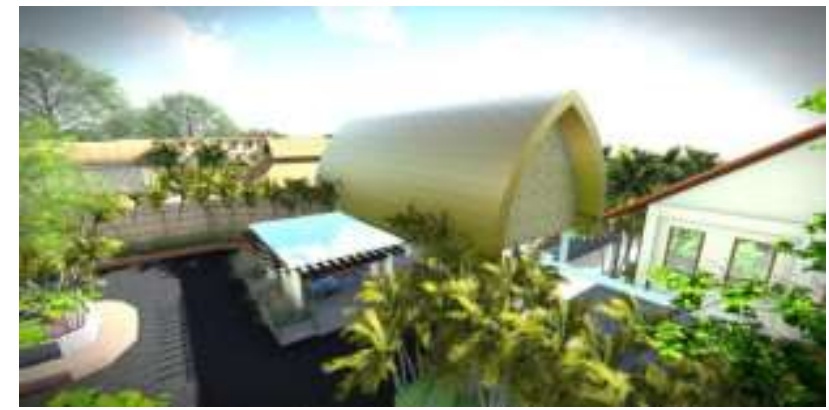

Fig. 1. Exterior appearance of the Lobby Building (source: Subagya)

The appearance of the lobby building is thick with the atmosphere of the Sasak architecture style of the Sasak granary formation, considering that the lobby is the first area to be addressed by guests which must be able to give a first impression that can indicate the characteristics of a regional location. The color selection in the appearance of the building which is in the white to yellow class is also to strengthen the atmosphere of Setangi Beach with yellow sand beach.

The atmosphere of Sasak architectural style is also thick in the entire building of the room units as the main facility with there are four types of room units with different facilities. The appearance of the building unit basically adopts the Sasak granary building but changes both in size and appearance according to the function and needs. In terms of the selection of dominant material, it still uses natural materials that are easily available in the vicinity.

\section{B. Adapting Climate and Saving Energy}

Basically the constituent elements of space are divided into three elements namely the bottom element (floor), the side element (wall) and the upper element (ceiling). The choice of material in the constituent elements of space will be the basis of the success of the application of the industrial interior concept. The application of industrial concepts certainly influences the choice of material in order to create the impression of masculine, rude but still providing comfort and of course affordable. For more details, see Figure 2 below.

The emphasis of the principle of environmentally friendly buildings conical on how to design buildings that are able to be sensitive to climate and save energy. [4], said that one of the environmentally friendly buildings applies ventilation in the building which as a medium for lighting and natural maintenance of the building as well as to support the comfort of the community.

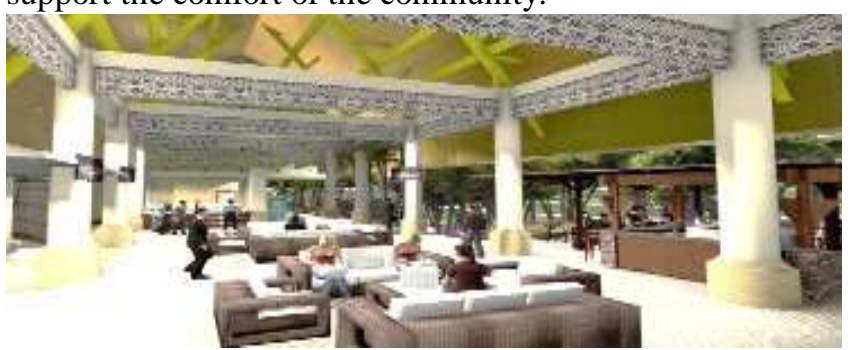

Fig. 2. Emphasis on Principles Sensitive to Climate and Energy Saving in 
Lobby Buildings (source: Subagya)

The design of the lobby building display at the eco resort carries the concept of semi-open so it is very capable of optimizing the use of natural energy sources in the form of wind and sunlight as a source of escort and lighting in buildings to support comfort in space. Wind and sun circulation can enter through the semi-open body of the building and on the lattice of synthetic fabric with Lombok weaving motifs on the roof and the orientation of the building facing east and west to optimize the reception of wind circulation and sunlight. Besides, from the arrangement and orientation of the mass of the lobby building, the proportion of the building is rather high (see figure 2.) where the in-terior atmosphere has a building height of more than 12 meters so as to provide flexibility to the wind circulation in the room so that hot air will quickly climbed to the highest point of the room then exited through the lattice with synthetic fabric media on the roof.

There are several types of supporting facilities, one of which is a facility that serves as an area that accommodates the activity of eating, drinking, hanging out and relaxing. Restaurants in the eco resort as a place to accommodate eating and drinking activities, small meetings, and relaxing for guests who stay overnight or not. This restaurant also needs to adopt the principles of being sensitive to climate and saving energy from the design of the building's own planning, as in figure 3 .

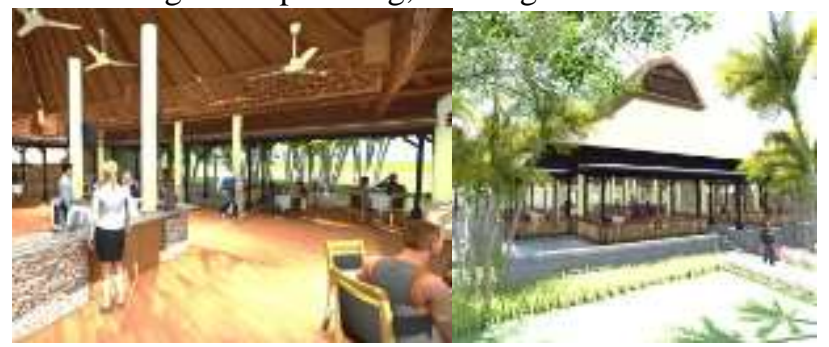

Fig. 3. Emphasis on Principles Sensitive to Climate and Energy Saving in Lobby Buildings (source: Subagya)

Similar to the concept of building design with a lobby, this restaurant also carries the appearance of a semi-open building in order to optimize the optimal utilization of natural energy sources from wind and sunlight as a medium for natural dissipation and lighting in buildings. Natural lighting during the day can enter through the body of a semi-open building and as well as on the roof through a lattice in the form of a wood lotter at the same time the loster also functions as a medium of air circulation in buildings. Then, in the aspect of applying the restaurant building materials it also carries natural materials, such as the application of the dominant material using wood on the floor of the building and using Imperata as a roof covering on the grounds that it is easy to obtain in locations nearby so as to be able to save energy during material distribution and reduce carbon footprint emissions that can pollute air pollution. The use of alang-alang material as a roof covering because reeds are a material that is insulating against heat so as to be able to make the civitas in the restaurant remain comfortable.

The room unit is the main facility at this resort with four divisions ranging from standard to luxurious namely, one bedroom type studio, junior suite room, suite room, president suite room with the appearance of each building basically adopting the basic lumbing sasak formations but by experiencing modification of several aspects in order to meet all the needs of the activities of the community at eco resorts.

President suite room is one of the four types of room units in the resort and one of the room units with the most complete facilities with 3 bedrooms complete with open bath tub, family room, dining room, pantry, mini pool, relaxing area, yoga area and a sunbathing area with a 2 story building view (see figure 4 ).

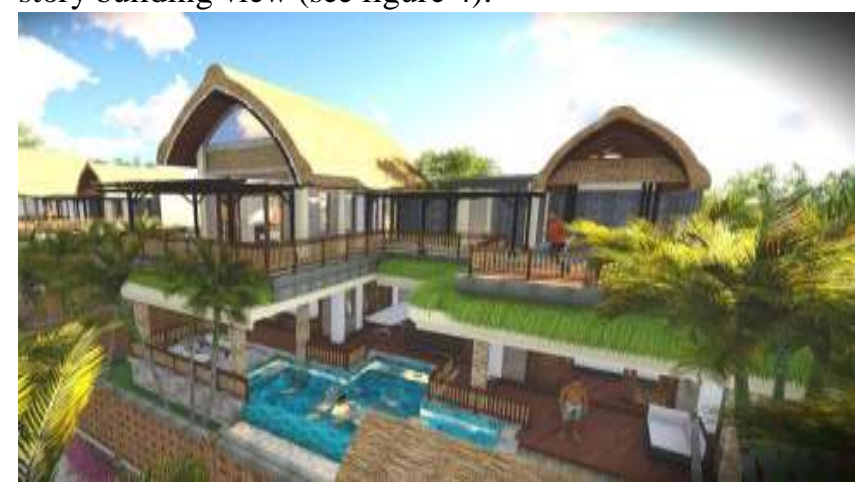

Fig. 4. Special Emphasis on Design of an Ecological President Suite Room (source: Subagya)

With the appearance of a two-story building it is possible to get more sun and air light intensity because it is not obstructed by objects around it. In utilizing these conditions the design of the building adopts the concept of semi-open buildings as an effort to provide flexibility of light and wind into the building not only that, the application of light shelves is also applied to parts of the building's roof to maximize natural lighting while providing a view at night and placing the pool swimming pool is related to the function of the main room with the aim of providing high humidity so that natural air conditioning is cooler and as a medium of light reflection which aims to save energy and apply a green roof as a medium that is able to improve air quality due to pollution [5].

Suite room is a residential unit with 2 bedroom facilities, pantry, dining area, and mini pool with the appearance of a floor building with the basic formations adopting the Sasak granary formation, which is illustrated in Figure 5 below. 


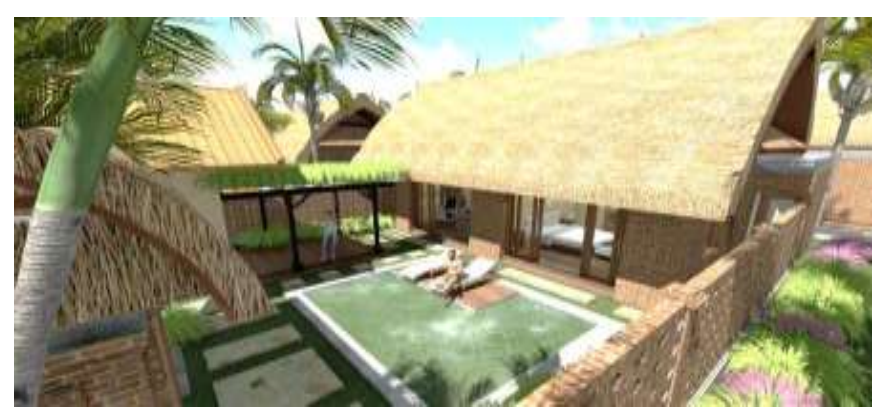

Fig. 5. Design in Optimizing the Utilization of Natural Energy in the Suite Room

In the suite room residential units strongly apply the principles of ecological architecture from climate sensitivity and energy saving from optimizing the use of natural energy from sunlight and wind as a media for lighting and natural ventilation from the application of the lotter on the roof as a medium for air entry, mini placement pool at the center of the unit area as a medium for light reflection and the use of easily available materials such as bricks, wood and reeds that are able to harmonize with the climate on the site.

There is the last type in the suite room class, which is a junior suite room which is a room unit with 1 bedroom, 1 bathroom and terrace facilities but has the closest access to the main pool and has a direct view orientation to Setangi Beach with a typical building view sasak barn. (see figure $6)$.

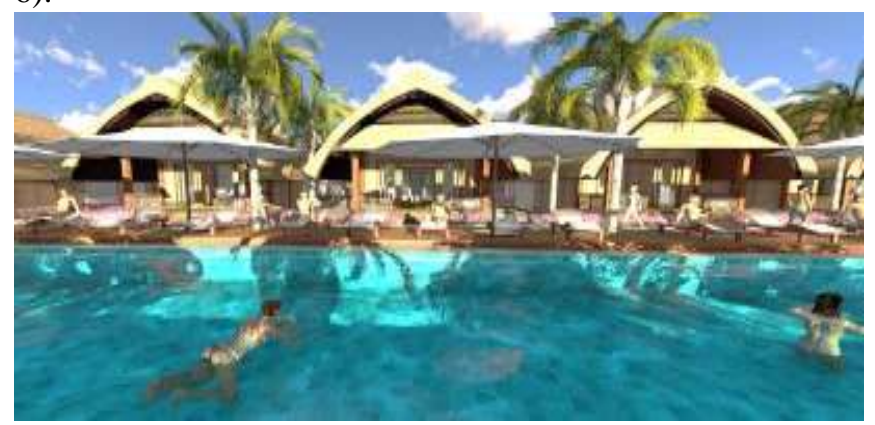

Fig. 6. Design in Optimizing the Utilization of Natural Energy in the Suite Room

In the picture above, it can be seen how the building's appearance carries the base of the Sasak barn to make it in harmony with the surrounding environment. In addition, in order to optimize the application of the ecological principles of the dominant building design using seseh wood that is widely available around the site as well as the application of Imperata grasses as a medium for reducing solar heat in buildings and at the same time this material is available in abundance around the site. In the interior, in the area of the wall above the entrance from the terrace to the bedroom there is a wood and glass lotter as an additional medium of lighting and natural ventilation in the room so as to save energy.

\section{Application of Renewable Energy Sources and Wastewater Treatment}

In addition to material selection, spatial planning and design planning at the eco resort also applies several renewable energy principles to one of the buildings in order to optimize the utilization of natural energy sources, such as one bedroom type studio buildings using solar panel media placed on the roof top of the building. in order to process solar heat into electrical energy that can be used in night lighting resources in garden lights so as to be able to save energy because according to Heinz Frick (1998), said one of the eight criteria for environmentally friendly buildings is that buildings must be able to apply sources renewable energy and treat waste well. Whereas wastewater treatment in the form of rainwater at this eco resort is reused as a media for vegetation maintenance which was previously accommodated in a bioswales under the guest pedestrian access in the site which then flowed out to the out-let pipe with the help of pumps illustrated in figure 7 .

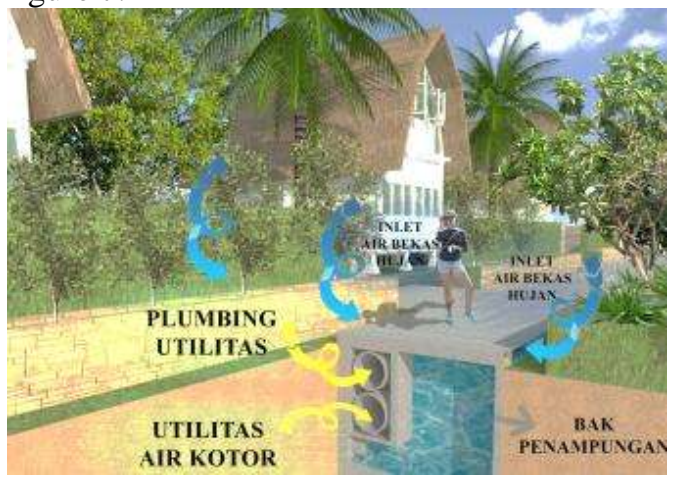

Fig. 7. Application of Lobster and Glass on the walls of the Junior Suite Room.

\section{Decoration and Artwork}

In addition to material selection, spatial planning and design planning at the eco resort also applies several renewable energy principles to one of the buildings in order to optimize the utilization of natural energy sources, such as one bedroom type studio buildings using solar panel media placed on the roof top of the building. in order to process solar heat into electrical energy that can be used in night lighting resources in garden lights so as to be able to save energy because according to Heinz Frick (1998), said one of the eight criteria for environmentally friendly buildings is that buildings must be able to apply sources renewable energy and treat waste well. Whereas wastewater treatment in the form of rainwater at this eco resort is reused as a media for vegetation maintenance which was previously accommodated in a bioswales under the guest pedestrian access in the site which then flowed out to the out-let pipe with the help of pumps illustrated in figure 7

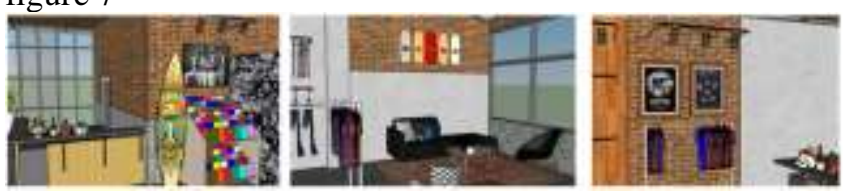


Fig. 4. Decoration (source: Ranubhuana)

\section{CONCLUSION}

In this environmentally friendly resort planning, several principles of environmentally friendly buildings have been applied to the design of both the appearance and the system that is applied to the building but does not reduce the function of the building and the value of comfort in the building. Such as being able to reduce the use of artificial energy sources in buildings by applying the appearance of semi-open buildings to several building functions so as to be able to provide more sunny air and air entry media, applying openings to the roof in the form of light shelves as media to enter sunlight, placement of swimming pools in the section with the main function as a medium for light reflection, selection of materials that are easily obtained in the surrounding environment in order to reduce carbon footprint, apply a green roof, apply renewable energy sources with solar panel media and are able to process waste water used for rainwater for reuse as a media for treating vegetation in eco resorts so as to reduce the use of natural resources. Thus, this eco resort planning can be said to be a building that is able to be in harmony with the environment by reducing the impact on the environment due to waste production at the resort in the service of services to guests. On the other hand, the planning of a commercial building function like this resort needs special treatment in terms of design considering the function of the resort accommodates quite complex activities and of course requires quite a lot of energy sources and produces quite a lot of waste resulting from service activities to guests, so we need to think about how to plan buildings that are capable of having a negative impact on the environment minimally so as not to damage the ecosystem around the site and be able to maintain the beauty of the surrounding nature and it is hoped that the ecological principles in this eco resort design can be used as guidelines in planning a building next.

\section{REFERENCES}

[1] Pendit, Nyoman S., "Ilmu Pariwisata", Jakarta:Akademi, 1999.

[2] Kwok.G.Alison, Walter T. Grondzik., "Green Studio Handbook", Oxford: Elsevier Inc, 2007.

[3] Stang, Alanna, Christopher Hawthorne, "The Green House: New Directions in Sustainable", 2005.

[4] Frick, Heinz, "Dasar-Dasar Arsitektur Ekologis Edisi ke-1", Yogyakarta: Yayasan Kanisius, 1998.

[5] Frick, Heinz. "Arsitektur Ekologis - Seri Eko - Arsitektur 2", Yogyakarta: Yayasan Kanisius, 2001. 